\title{
Temperature distribution analysis of July 2001 Mt. Etna eruption observed by the airborne hyperspectral sensor MIVIS
}

\author{
Valerio Lombardo and Maria Fabrizia Buongiorno \\ Istituto Nazionale di Geofisica e Vulcanologia, Roma, Italy
}

\begin{abstract}
On 17th and 18th July 2001, several fractures opened on Mt. Etna southern flank generating different lava flows spreading both in Valle del Bove and towards Nicolosi. On 29th July the image spectrometer MIVIS was flown over Mt. Etna to acquire high-resolution images of the eruption. The MIVIS airborne campaign was planned simultaneously with TERRA, EO-1 and Landsat 7 satellite acquisitions, in order to compare hyperspectral and multispectral data referred to active lavas. This work focuses on the thermal mapping of lava flows, taking advantage of MIVIS sensor high technical performances. The MIVIS high spatial resolution allows a detailed analysis of the lava flow topographic distribution. Its 12 bit dynamic range consents an estimate of the temperature even for the «hottest» pixels. The main target of this work is the evaluation of the energy flux by means of remote-sensing techniques. Surface temperature analysis was performed on distinct lava flows using the dualband technique. These quantities were compared with the integrated temperatures retrieved using the MIVIS thermal infrared bands. The influence of topography was also considered in the flux calculation using a Digital Elevation Model (DEM) of Mt. Etna.
\end{abstract}

Key words remote-sensing - volcano monitoring thermal infrared - dual-band technique

\section{Introduction}

Since 1992, the INGV Remote Sensing Group has carried out research based on optical imaging systems to study active volcanic areas. The Remote Sensing Group participated in several airborne campaigns with image spectrometers to acquire data on interesting volcanic sites and tectonically active areas (Salvi et al., 1992; Bogliolo et al., 1996; Buongiorno et al., 1999). Some major benefits come from remote-sensing when we aim to investigate hot volcanic targets (e.g., lava flows,

Mailing address: Dr. Valerio Lombardo, Istituto Nazionale di Geofisica e Vulcanologia, Via di Vigna Murata 605 00143 Roma, Italy; e-mail: lombardo@ingv.it fumaroles, etc.). First, optical sensors acquire data in areas not accessible during eruptive events. Second, the number of accessible sites is often inadequate to be representative of extended lava flows. Airborne sensors can image the entire flow surface and consent to estimate its global thermal status. Of course, direct measurements are necessary for data validation and calibration. The Mt. Etna 2001 eruption gave us the opportunity to assess remote-sensing techniques using high-resolution data. One of these techniques is the dualband method that allows the retrieval of the energy flux radiated from active lavas. Flux reports are lacking in literature and they are mostly derived from satellite data. Unfortunately, the restricted dynamic range ( 8 bits) of the spaceborne sensors like Landsat TM reduces the dual-band technique functioning (Glaze et al., 1989; Pieri et al., 1990) in the presence of high temperature targets (Pieri et al., 1990, Oppenheimer, 1991; Rothery et al., 1992; Flynn et al., 2000, 2001). When Landsat ac- 
quires on lavas, the pixels located around the vents or at the center of lava flows are often saturated in the infrared (IR) channels and therefore useless. As a result, the total energy flux calculated using these IR bands is underestimated. The MIVIS sensor is equipped with a 12 bit dynamic range detector that avoids saturation for most of the pixels. This study reports the statistics of the energy flux generated from the lava flow as imaged by MIVIS on 29th July 2001; results are compared to those existing in literature.

The energy flux depends on the extension of the radiating surface and thus is a function of the pixel size of the scene. Optical resolution of the sensor, flight altitude and topographic elevation of the scene constrain the pixel size of the image. Here, we discuss the influence of the topographic elevation on flux calculations, when the size of pixels in the scene varyies according to altitude variations.

\section{2001 Mt. Etna eruptive event}

The July-August 2001 eruption was characterized by an intense and differentiated activity; here follows a brief chronology of the main events (Behncke and Neri, 2003). On 17th July a NS trending eruptive fissure, opened on the southeastern flank of the SE crater at about $2950 \mathrm{~m}$ a.s.l. (see fig. 1). Two further N-NE trending en échelon fissures opened at $2700 \mathrm{~m}$ a.s.l. and started to spill lava towards Pian del Lago. The following day an eruptive fissure opened close to Mt. Calcarazzi and a new lava flow departed towards Mt. Silvestri. Coalescent pit-craters, characterized by an increasing phreatomagmatic ash emission, come out at Piano del Lago on the 19th. This emission lasted five days before switching into Strombolian activity, and giving rise to a scoria cone. On 20th July a new fissure emitting lava flows south-east-

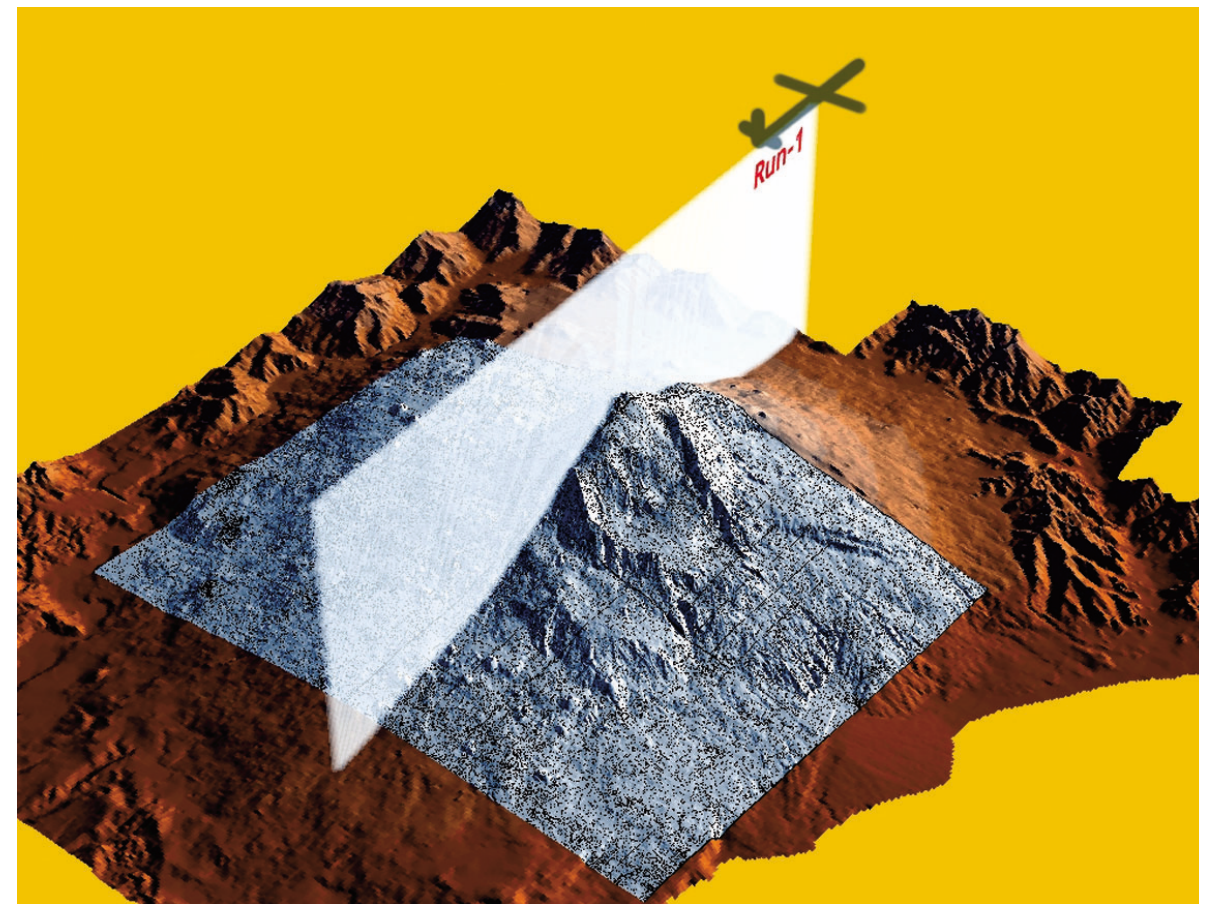

Fig. 1. Flying path of the MIVIS sensor installed on a CASA aircraft over Mt. Etna during the July 2001 eruptive event. 
ward appeared in Valle del Leone, at $2600 \mathrm{~m}$ a.s.l. Intense fire-fountaining activity was present in the lower portion of the $2100 \mathrm{~m}$ fissure and phreatomagmatic activity was observed in the upper part. On the 23rd a small fissure opened in the southeastern flank of SE crater giving origin to a lava flow that expanded eastward. Another small fissure, opened between the SE and the NE craters, spread out very modest quantity of magma. Between July 26th and 28th, distinct lava flows started to flood from the base of the scoria cone at $2550 \mathrm{~m}$ : they were located at the SE base of the cone, close to the Montagnola, eastward in the Valle del Bove and on the NW side were they merged to the SW vent lava flow. On the 27th the lava effusion at $2700 \mathrm{~m}$ shifted to $2640 \mathrm{~m}$, producing a flow directed towards Mt. Nero, while the $2100 \mathrm{~m}$ lava front stopped completely.

\section{MIVIS airborne campaign on Mt. Etna}

The MIVIS instrument is an airborne image spectrometer acquiring in the range 0.4-2.5 and 8-12 m (see table I) owned by Consiglio Nazionale delle Ricerche (CNR, Progetto LARA) and operated by the Compagnia Generale Riprese Aeree (CGR). MIVIS was first employed in 1994 in Sicily. INGV organized the airborne acquisition on the Sicilian volcanoes and a field campaign (Bogliolo et al., 1996). In 1997, a sec- ond MIVIS campaign was organized in the frame of the EC project MVRSS (Cont.: CT960288) to study the volcanic plumes emitted by Etna and Stromboli (Buongiorno et al., 1999). MIVIS data were successfully used to develop stable techniques to retrieve $\mathrm{SO}_{2}$ columnar abundance and analyze the thermal features of active lava flows and hot emissions (Teggi et al., 1999). Results may be used for systematic monitoring of active volcanoes by means of satellite image data. During the 2001 Etna eruption, INGV organized an airborne campaign with the MIVIS instrument to acquire high-resolution images on the active lava flow that was heading towards the town of Nicolosi.

The campaign took place on 29th July, 2001 (fig. 2) and was concomitant with the ASTER sensor (TERRA satellite) acquisition. The MIVIS acquired 8 flight lines in a radial pattern crossing over the summit area. The 8 flight lines covered the entire Etna structure (approximately 40 by $40 \mathrm{~km}$ to perform a fusion with satellite data). The flight altitude was $6400 \mathrm{~m}$ a.s.l. and subsequently the pixel ground resolution ranged between 6 and $12 \mathrm{~m}$, depending on the surface elevation (fig. 1).

\section{Dual band technique}

According to the Crisp and Baloga (1990) thermal model, we assume the energy flux of

Table I. MIVIS sensor technical details (A) and related spectral range (B).

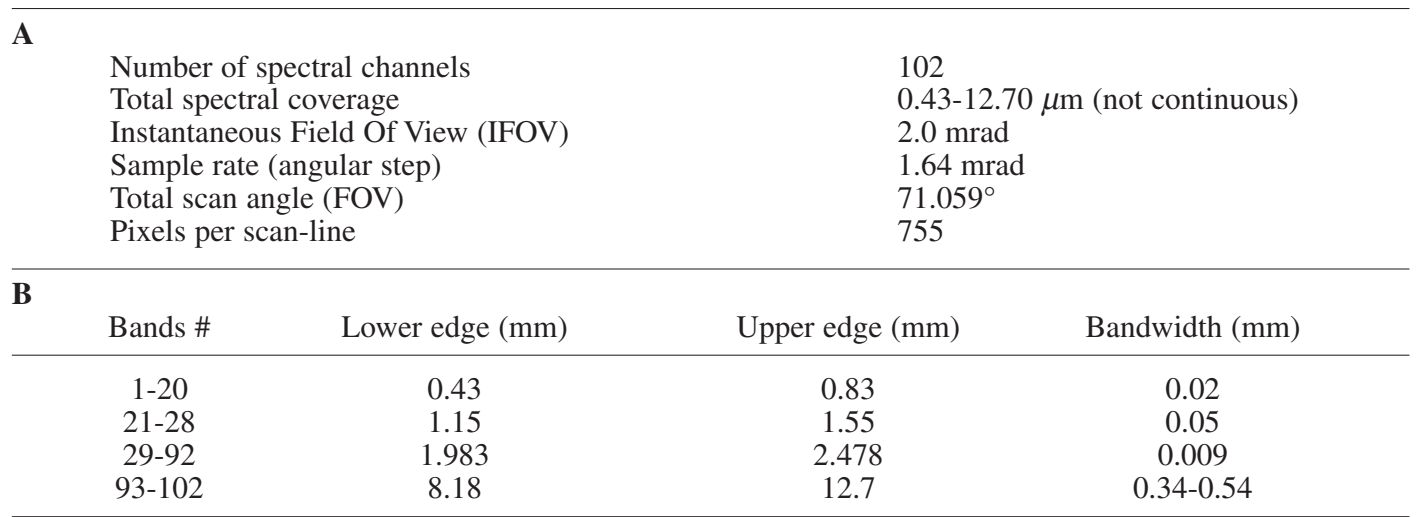




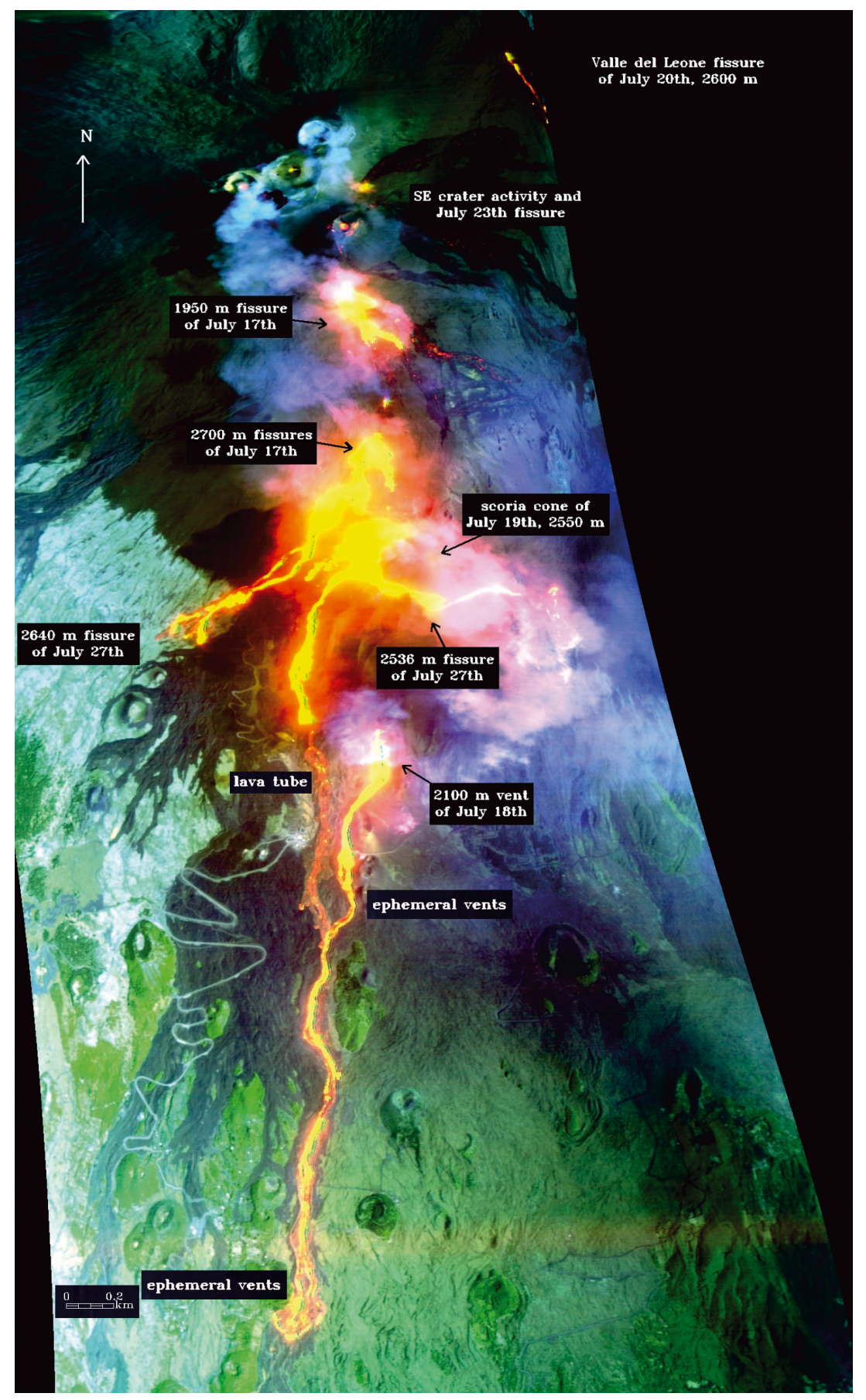

Fig. 2. Geocoded RGB $(54,28,13)$ MIVIS bands; average pixel size is $8 \times 8 \mathrm{~m}$. 
the Etnean lava flows as a function of the fractional area of two thermally distinct radiant surfaces. The largest surface corresponds to the coolest crust of the flow, whilst the smaller area is related to the hot fractures of the crust. The temperature radiated from the cracks is supposed to be similar to the temperature of the melted core of the flow, about 2-4 times warmer than the crust.

The dual band technique allows the crust temperature $\left(T_{c}\right)$ and the fractional area $\left(f_{h}\right)$ of the lava flow hot cracks to be calculated. This method requires the availability of a sensor with two bands within the short wave infrared (SWIR) region of the spectrum to calculate the "sub-pixel' temperature of the lower and hot fractions (Dozier, 1981; Matson and Dozier, 1981; Wan and Dozier, 1989). The dual-band technique was performed using different sensors like AVHRR (Mouginis-Mark et al., 1994; Harris et al., 1995a, 1997; Harris, 1996), ATSR (Wooster and Rothery, 1997a,b) and Landsat Thematic Mapper (TM) (Rothery et al., 1988; Glaze et al., 1989; Pieri et al., 1990; Oppenheimer, 1991; Flynn et al., 1994; Harris et al., 1998; Pieri and Buongiorno, 2001; Wright et al., 2001). These satellite sensors are characterized by low spatial resolution (AVHRR and ATSR, $1 \mathrm{~km}^{2}$ ) and fairly limited dynamic range (Landsat TM, 8 bits) with respect to the MIVIS airborne sensor (see table I). We apply this two components model using MIVIS bands $28(1.525 \mathrm{~m})$ and $53(2.188$ $\mathrm{m})$ to solve a dual-band equation system where three unknown quantities are represented by the temperature of the crust $T_{c}$, the temperature of the inner core $T_{h}$ (assumed to be represented by the characteristic temperature of the fractures), and the fractional area of the hottest component of the surface, $f_{h}$. We give an established value to one of these quantities in order to solve the equation system. The relatively constant innercore temperature along the whole length of the flow, as well as the low heat capacity and very low thermal diffusivity values for Etna lavas, suggest assuming $T_{h}$ as a boundary condition. Measurements of solidus temperatures (Gauthier, 1973; Archambault and Tanguy, 1976; Calvari et al., 1994; Global Volcanism Network, 1996,1999 ) yield to a $T_{h}$ value equal to $1080{ }^{\circ} \mathrm{C}$. It was tested that bands $1.525 \mu$ and $2.188 \mu$ are the most responding channels in the dual-band algorithm, therefore they were chosen for the temperature calculation. These bands were also selected since they are close to the corresponding two SWIR bands of the Landsat TM and ASTER (1.65 $\mu$ and $2.22 \mu$ respectively) to allow a multi-sensor comparison of $T_{c}$ and $f_{h}$. The dual band system equation applied to the MIVIS bands can be summarized as follow:

$$
\begin{aligned}
& R \alpha=f_{h}\left(R_{h} \alpha\right)+\left(1-f_{h}\right) R_{c} \alpha \\
& R \beta=f_{h}\left(R_{h} \beta\right)+\left(1-f_{h}\right) R_{c} \beta
\end{aligned}
$$

where $R \alpha$ and $R \beta$ are respectively the total radiance values detected by the sensor for band $1.525 \mu$ and $2.188 \mu ; R_{h} \alpha$ and $R_{h} \beta$ are the radiance values calculated for the same bands using Planck equation by setting $1080{ }^{\circ} \mathrm{C}$ as the hottest temperature for Etna lavas, referred as $T_{h} ; f_{h}$ is the fractional area of the hottest temperature component.

$R_{c} \alpha$ and $R_{c} \beta$ are related to the crust temperature $T_{c}$ throughout the Plank equation

$$
R(\lambda)=\frac{\varepsilon C 1}{\lambda^{5} \pi\left(\exp \left(C 2 / \lambda T_{c}\right)-1\right)}
$$

where $\varepsilon$ is the spectral emissivity, estimated by means of sample spectra, $\lambda$ is the wavelength, $T_{c}$ is the crust temperature, and the constants $C 1$ and $C 2$ have values 3.74151 $10^{-16}\left[\mathrm{Wm}^{2}\right]$ and $1.438810^{-2}[\mathrm{mK}]$, respectively. We apply a digital filter, already tested on Landsat TM images (Lombardo et al., 2003), to single out the radiant pixels of the flow in MIVIS images

$$
0.0657<\tau 1<\left(0.001043 T_{h}-0.28862\right)
$$

where $\tau 1$ is the ratio between MIVIS bands 28 and 54 and $T_{h}$ is set to $1080{ }^{\circ} \mathrm{C}$.

\section{Lava-flows temperature analysis}

Temperature retrieval was performed with two distinct methods: i) using the thermal infrared bands, 'pixel-integrated' temperature; ii) 
applying the dual-band technique, 'sub-pixel' temperature (Glaze et al., 1989). The pixel-integrated temperature $T_{p}$ was derived from the total radiance $R_{\mathrm{tot}}$ detected in the thermal band $\lambda$ by way of the inverse Planck function

$$
T_{p}=\frac{C 2}{\lambda \ln \left(\left(\varepsilon C 1 \lambda^{5} / \pi R(\lambda)\right)+1\right)} .
$$

The 10 temperature images retrieved from the MIVIS TIR bands (table I) were analyzed using the 'principal-components' transformation (PC). This transformation allows a rearrangement of the bands to compress most of the images variance into the first ' $\mathrm{PC}$ ' and confine the noise in the remaining ' $\mathrm{PC}$ '. We used the first $\mathrm{PC}$ image $\left(\mathrm{PC}_{1}\right)$ to highlight the thermal difference within the analyzed scene.
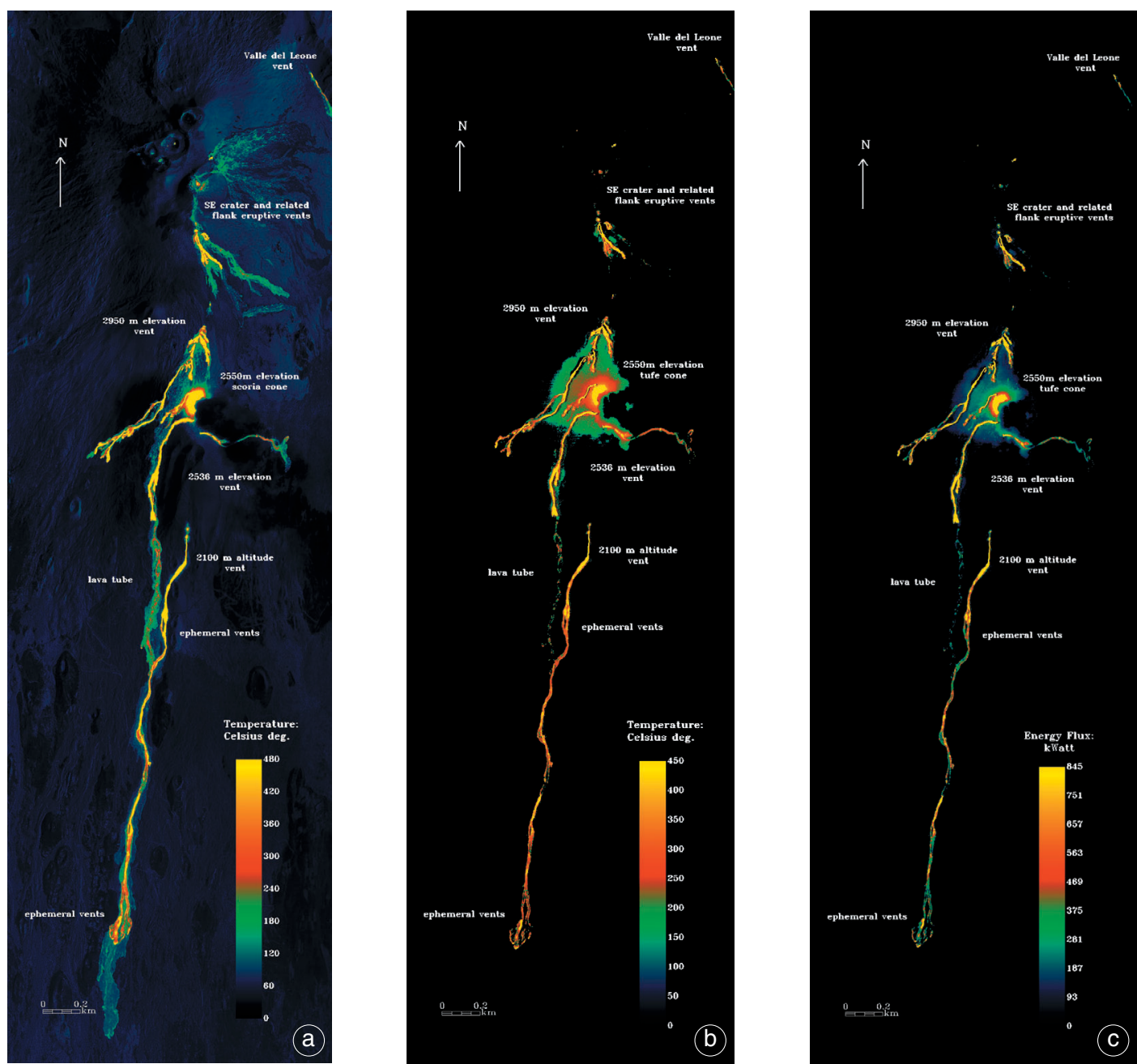

Fig. 3a-c. a) Principal components transformation on the MIVIS thermal infrared bands and integrated temperature mapping of the lava flows. b) Crust temperature distribution retrieved by using the dual-band technique. c) Energy flux calculated for the radiant pixels. 
The pixel-integrated temperature would be an average value between $T_{h}$ and $T_{c}$ and not completely representative of the effective thermal structure of the pixel. Nevertheless, this representation is a powerful instrument for thermal comparison of different lava flows. $T_{p}$ distribution derived from the 29th July image is displayed in fig. 3a. Some interpretations can be retrieved from the analysis of this figure:

i) The highest temperatures correspond to main vent locations where we find a maximum $T_{p}$ of $480{ }^{\circ} \mathrm{C}$ for non-saturated pixels.

ii) Comparable temperatures are detectable for ephemeral vents located in some cases very far from their sources. Usually, this occurs when tunneling phenomena are in progress.

iii) $T_{p}$ values between 140 and $280{ }^{\circ} \mathrm{C}$ characterize tunneling structures, with peaks of $300{ }^{\circ} \mathrm{C}$ at the vents.

iv) Different $T_{p}$ distributions allow the identification of overlapping flows (e.g., lava originated from the $2100 \mathrm{~m}$ vent partly covers the previous flow started from the scoria cone at $2550 \mathrm{~m}$ ).

Dual-band solutions allow a more accurate estimation of the thermal budget. Figure $3 b$ shows the $T_{c}$ spatial distribution retrieved using the dual-band method. This figure shows the same features already observed in the $\mathrm{PC}_{1}$ image. However, structures like lava tubes appear more detailed in the $T_{p}$ distribution than in the $T_{c}$ one. This is due to the peculiar structure of the lava tube that is not consistent with the Crisp and Baloga (1990) thermal model. When the magma begins to stream into the tunnel, the sensor can detect only the temperature corresponding to the solidified ceiling crust of the tube. Therefore, dual-band solutions are strictly located in those portions of the tube where lava spreads out from local fractures. Moreover, the Principal Components Analysis (PCA) uses the TIR bands while the dual-band technique requires two bands in the SWIR region of the spectrum. Therefore, the PCA image shows the temperature structure of the lava tube in much more detail.

So, why should we use dual-band solutions to investigate the lava activities?
The pixel-integrated temperature is a rough quantification of the complex lava structure. Dual-band solutions allow a more realistic approximation of the lava thermal status and thus a better estimate of the energy flux.

\subsection{Energy flux and thermal budget}

Once $T_{h}, T_{c}$ and $f_{h}$ are known, the energy flux can be estimated (Pieri et al., 1990) by

$$
Q=\varepsilon A_{\text {pix }} \operatorname{sbk}\left(T_{h}^{4} f_{h}+T_{c}^{4}\left(1-f_{h}\right)\right)
$$

where $\varepsilon$ is the emissivity, $A_{\text {pix }}$ is the average area of the pixel and $s b k$ is the Stefan-Boltzman constant (eqs. (5.1) and (5.2)). $Q$ is the energy radiated from the area of a lava pixel. The size of this area depends on the spatial resolution of the pixel. This is related to the Instantaneous Field Of View (IFOV) of the sensor, the flight altitude and the topographic elevation of the imaged surface. Figure $3 \mathrm{c}$ shows the radiant contribution of the lava flow, and returns the energy flux for each pixel in $\mathrm{kW}$. The maximum $Q$ value in the image is $844 \mathrm{~kW}$, while the mean value is about $232 \mathrm{~kW}$ for an average pixel area of $8 \times 8 \mathrm{~m}^{2}$, according to the MIVIS IFOV (2 $\mathrm{mRad})$ and the mean altitude of the scene (2600 $\mathrm{m})$. This can be compared with the mean flux of $73.5 \mathrm{~kW}$ for the 1984 Etna Eruption (Pieri et al., 1990), for Lascar, Erebus, and Erte's Ale of 34.3-112.7 kW (Glaze et al., 1989). Our results are slightly higher than values available in literature, which are mostly derived from satellite data like Landsat TM and AVHRR. However, such a difference can be related to the higher dynamic range of MIVIS (12 bits) compared with the range of the spaceborne sensors (8 bits) used in the referenced papers. On the one hand, MIVIS enhanced performance allows higher temperature estimations; thus, higher $Q$ mean values are derived from our calculations. On the other hand, MIVIS encoding avoids saturation even for the hottest pixels. Therefore, more unsaturated pixels contribute to the total $Q$ estimate. Contributions from each single flow are detailed in fig. 4. 


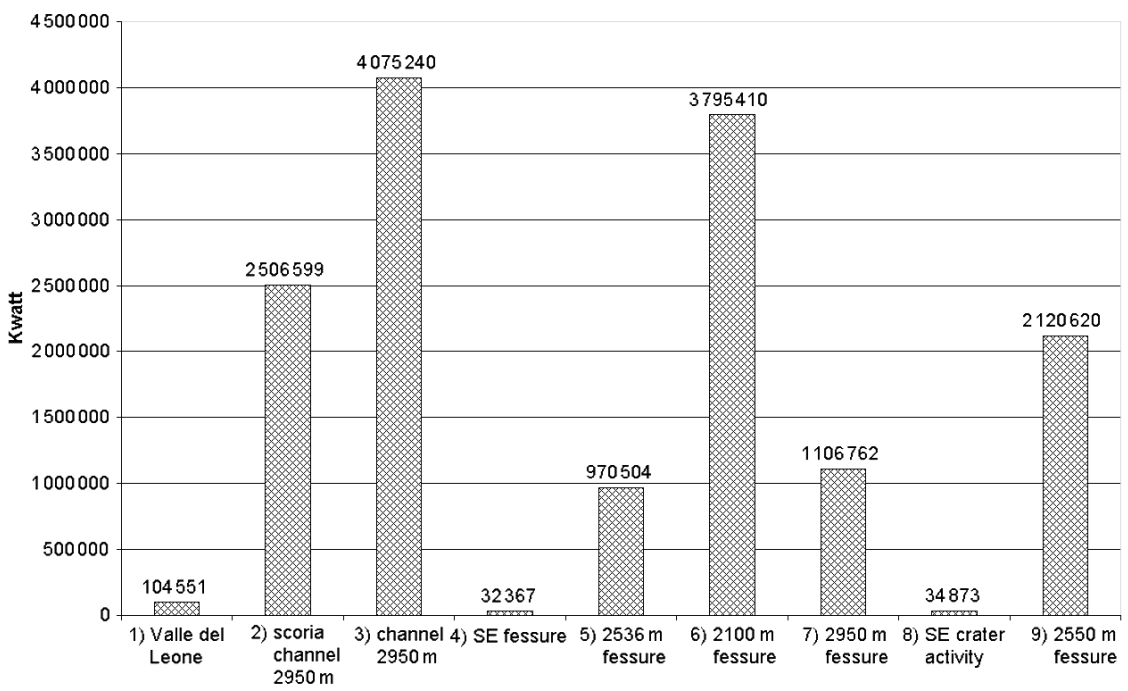

Fig. 4. Energy flux contribution of the distinct active lava flows on 29th July 2001.

\subsection{Pixel-size accuracy control on flux retrieval}

This section aims to analyze the energy flux estimation affected by pixel size variations due to topographic changes. The energy flux is a function of the pixel area, as derived from eq. (5.2). The technical features of the instrument (e.g., the IFOV) and the relative distance between flight altitude and ground elevation are the main factors influencing the pixel size. The IFOV is a technical constant of the sensor (table I) and the aircraft flight altitude varies in a very narrow range (typically less than $10 \mathrm{~m}$ in normal environmental conditions). The element that mainly affects the pixel size is the topography within the scene. This is true for airborne sensors only; satellite orbits are so much higher compared to earth relief, that the contribution of topography may be neglected. The Mt. Etna area covers a surface of about 40 by $40 \mathrm{~km}$, ranging in altitude from $0 \mathrm{~m}$ up to $3300 \mathrm{~m}$ at its summit crater area. This means that pixel size is scaling from $12.8 \mathrm{~m}$ to $6.2 \mathrm{~m}$, corresponding to a surface of about $163.8 \mathrm{~m}^{2}$ and 38.4 $\mathrm{m}^{2}$ respectively. It follows that using a constant average pixel size for the entire scene can lead to large errors in energy flux estima-

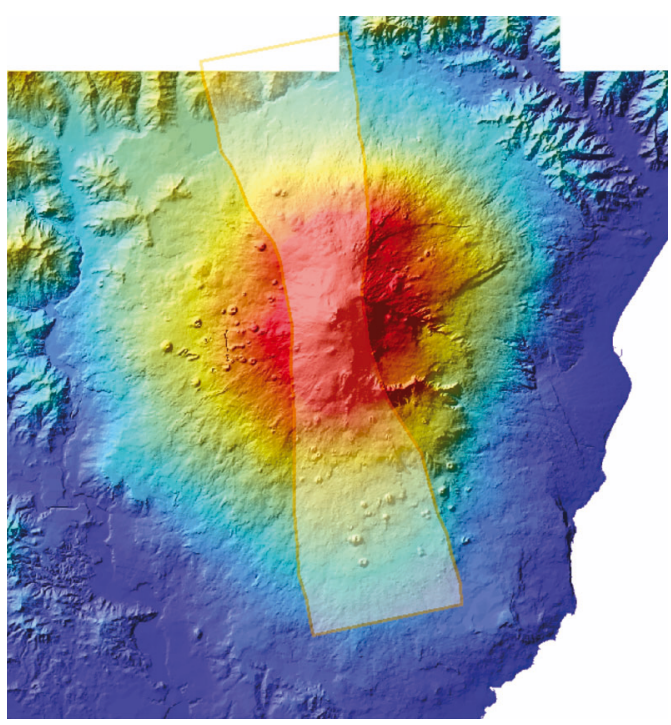

Fig. 5. Effective recorded surface according to different pixel-sizes due to topographic variations.

tion. Figure 5 shows the real shape of the surface as imaged by MIVIS during its flight over Mt. Etna. The hourglass shape is due to 


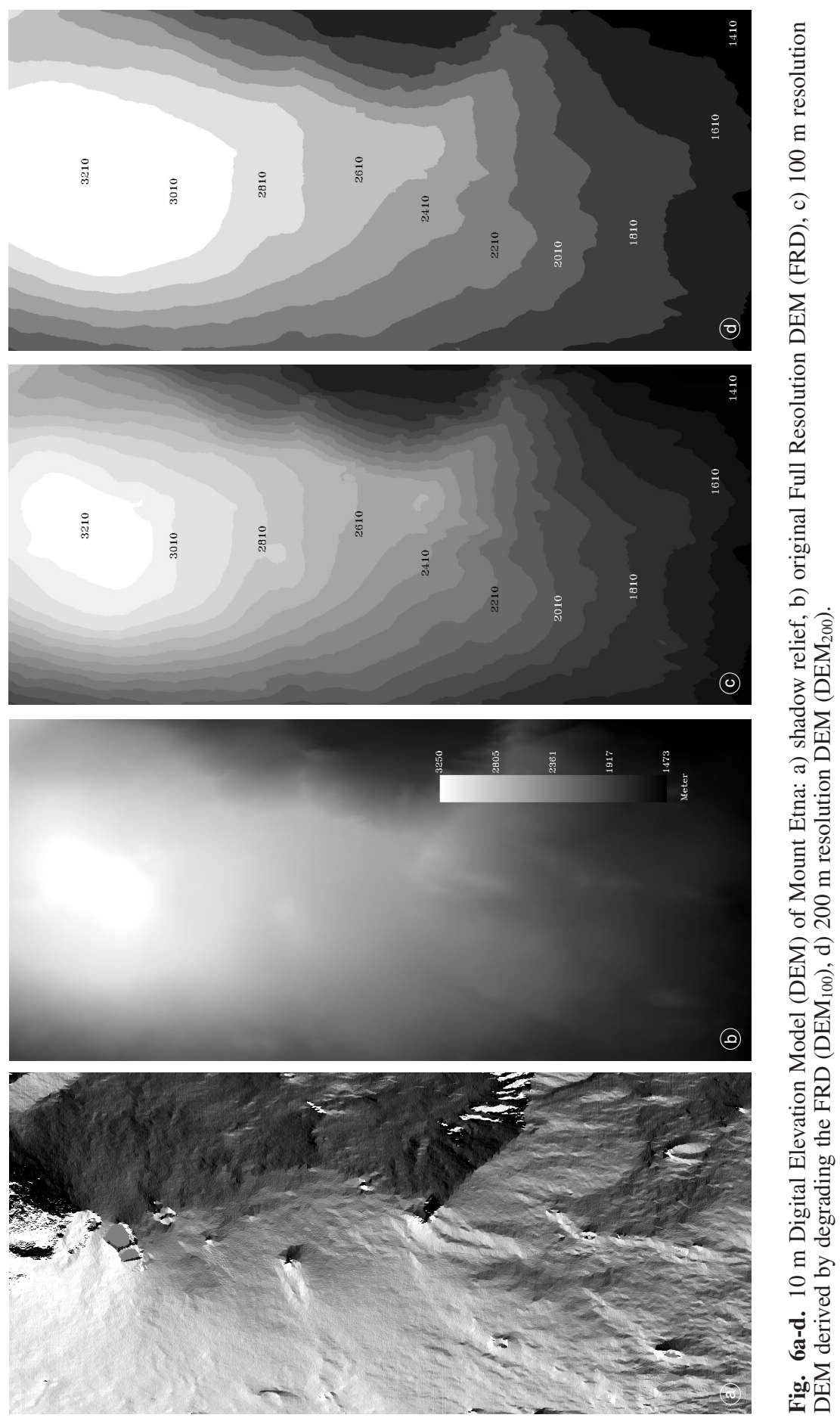

1225 
the pixel size variation corresponding to mountain relief. We calculated the effective surface associated with each pixel by using a $10 \mathrm{~m}$ resolution Digital Elevation Model (DEM). This approach allows a remarkable accuracy in the energy flux calculation. Figure 6a,b shows the Shaded Relief (SR) and the original Full Resolution DEM (FRD). The mean energy flux for FRD is $229.18 \mathrm{~kW}$ and the total flux is $14.682 \mathrm{MW}$. We studied the effect of the pixel-size accuracy on the flux retrieval by degrading the altitude resolution of the FRD. Two DEMs were generated (fig. $6 \mathrm{c}, \mathrm{d})$ with vertical resolution of $100 \mathrm{~m}$ and $200 \mathrm{~m}$ respectively $\left(\mathrm{DEM}_{100}\right.$ and $\left.\mathrm{DEM}_{200}\right)$. Total and mean values of the flux are only slightly affected (less than $0.09 \%$ ) when we use $\mathrm{DEM}_{100}$ or $\mathrm{DEM}_{200}$ in calculation instead

Table II. Energy flux statistics using different pixel-size values in flux calculation. DEM height is the topographic altitude corresponding to the IFOV of the instrument, the flight altitude and the pixel-size we set. For the entire lava-flow system the max, min and mean values were calculated for the energy flux. We also retrieved the total flux for the entire flow, the area of the active lavas and the energy radiated from surface unit.

\begin{tabular}{ccccccccc}
\hline \hline $\begin{array}{c}\text { Mode high } \\
(\mathrm{m})\end{array}$ & $\begin{array}{c}\text { DEM } \\
(\mathrm{kW})\end{array}$ & $\begin{array}{c}\text { Min } \\
(\mathrm{kW})\end{array}$ & $\begin{array}{c}\text { Max } \\
(\mathrm{kW})\end{array}$ & $\begin{array}{c}\text { Mean } \\
(\mathrm{kW})\end{array}$ & $\begin{array}{c}\text { STDEV } \\
(\mathrm{kW})\end{array}$ & $\begin{array}{c}\text { Tot flux } \\
(\mathrm{kW})\end{array}$ & $\begin{array}{c}\text { Lava area } \\
\left(\mathrm{m}^{2}\right)\end{array}$ & $\begin{array}{c}\text { Flux } \\
\left(\mathrm{kW} / \mathrm{m}^{2}\right)\end{array}$ \\
\hline Pixel size 7 m & 2910 & 0.79 & 646.60 & 177.42 & 186.53 & 11366363 & 3139234 & 3.62 \\
Pixel size 8 m & 2410 & 1.04 & 844.54 & 231.73 & 243.63 & 14845860 & 4100224 & 3.62 \\
Pixel size 9 m & 1910 & 1.31 & 1068.88 & 293.28 & 308.34 & 18789292 & 5189346 & 3.62 \\
Pixel size 10 m & 1410 & 1.62 & 1319.60 & 362.07 & 380.67 & 23196657 & 6406600 & 3.62 \\
DEM 200 m step & & 0.92 & 1319.60 & 228.19 & 250.04 & 14619262 & 3948923 & 3.70 \\
DEM 100 m step & & 0.89 & 1293.34 & 229.39 & 251.12 & 14696339 & 3964009 & 3.71 \\
Full resol. DEM & & 0.90 & 1279.79 & 229.18 & 250.57 & 14682545 & 3960794 & 3.71 \\
\hline
\end{tabular}

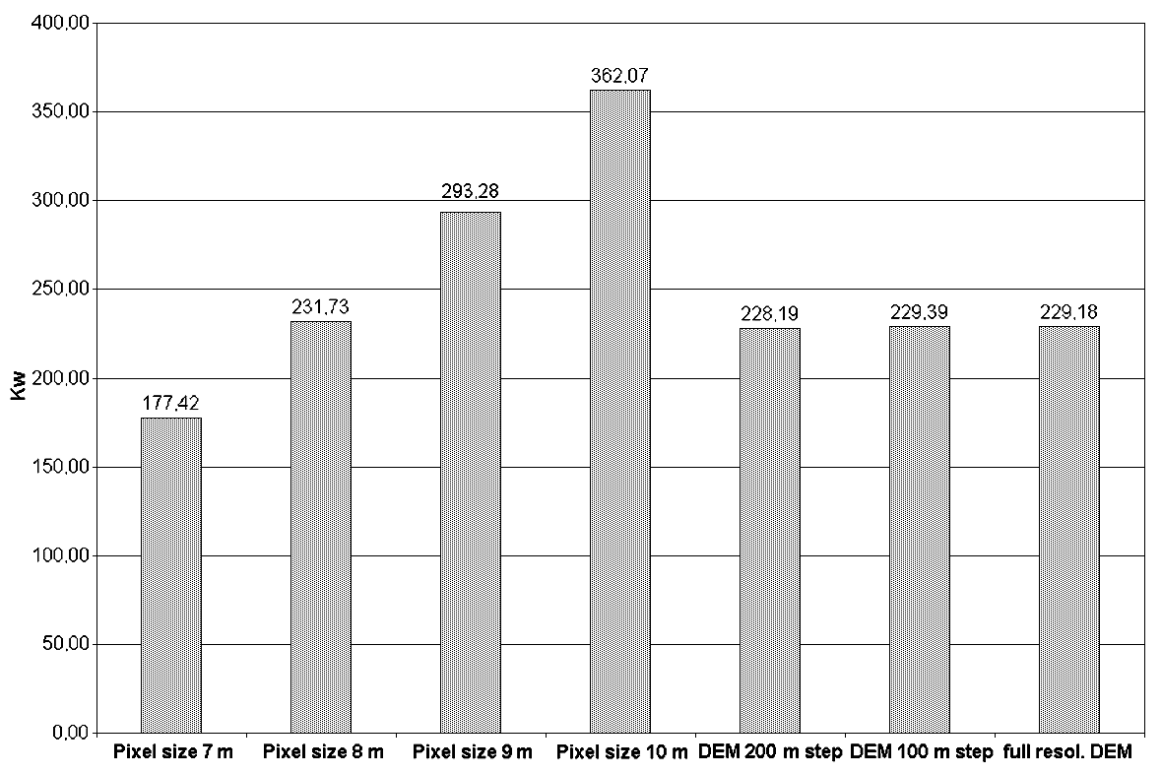

Fig. 7. Energy flux calculated on the entire image using constant values for the pixel-size (7, 8, 9, $10 \mathrm{~m}$ respectively) or values derived from a $10 \mathrm{~m}, 100 \mathrm{~m}$ and $200 \mathrm{~m}$ resolution DEM. 
of the FRD (table II). However, large differences may occur when we use constant pixelsize values in eq. (5.2). Energy flux was calculated by setting the pixel-size to $7,8,9$, and $10 \mathrm{~m}$ as shown in the column diagram of fig. 7. The mean flux corresponding to $7 \mathrm{~m}$ pixelsize is underestimated by $22 \%$ with respect to the FRD estimate, while the flux corresponding to $10 \mathrm{~m}$ is overestimated by $57 \%$.

We conclude that the total amount, the mean flux and all the other parameters strongly differ according to the pixel-size used in calculation (table II). The use of DEMs in energy flux calculation is strongly recommended, especially in the presence of extended flows, when differences in altitude between vent and lava-front are significant. The vertical resolution of the DEM must be consistent with these differences. However, large improvements in DEM resolution do not always correspond to improvements in energy flux accuracy.

\section{Conclusions and future work}

The 2001 airborne MIVIS campaign on Mt. Etna was extremely significant since once again the importance of remote sensing techniques has been highlighted. First, solutions obtained from dual-band calculation, $\left(T_{c}\right.$ and $f_{h}$ ) and information derived from them, like the energy flux, are extremely difficult to retrieve using different methods (e.g., by direct measurements). Second, the lava-flow geometry and its thermal structure are more detailed using airborne spectrometers than any other procedure. Third, the temperature distribution and the energy flux can be mapped in a short time after acquisition and data processing. The image data acquisition allows us to test remotesensing techniques for temperature retrieval. The dual-band method has been successfully applied to the radiant pixels of the lava flow. We can infer that: i) the dual-band technique is not dependent on the sensor architecture and performs adequately with airborne imaging spectrometers like MIVIS; ii) hyperspectral sensors provide high quality results; iii) this method maps volcanic events and analyzes complex and extended eruptions; iv) accuracy may be improved by using a digital elevation model for pixel-size outlining.

Finally, the simultaneous acquisition of MIVIS and ASTER highlights the importance of satellite data in volcanic monitoring. Our future work focuses on the comparison of data achieved by these sensors, possibly including the ALI and Hyperion data acquired by EO-1 the same day. Another target is the comparison between MIVIS and ASTER data for sulfur dioxide emissions in the Etnean plume.

\section{Acknowledgements}

We are grateful to Dr. Fawzi Doumaz for the GIS support and graphic creations.

Special thanks also to Dr. Piergiorgio Scarlato for providing us a detailed chronology of the events during the 2001 Etna eruption.

\section{REFERENCES}

Archambault, C. and J.C. Tanguy (1976): Comparative temperature measurements on Mount Etna lavas: problems and thecniques,. J. Volcanol. Geotherm. Res., 1, 113-125.

BeHnCKe, B. and M. Neri (2003): The July-August 2001 eruption of Mt. Etna (Sicily), Bull. Volcanol., 65, 461476.

Bogliolo, M.P., M.F. Buongiorno, S. Salvi, S. Teggi, S. Pugnaghi, M.J. Abrams, D.C. Pieri, V.J. Realmuto and T. Caltabiano (1996): Ground measurements of physical parameters at Vulcano island and Mount Etna in support of the MIVIS remote sensing campaign « $\mathrm{Si}$ cilia-94», ING Pubblication n. 577, pp. 67.

Buongiorno, M.F., L. Merucci, F. Doumaz, S. SAlvi, M.P. Bogliolo, S. Pugnaghi, S. Teggi, S. Coradini, L. Lumbroso, A. Sterni, T. Caltabiano and V. Carrere (1999): MVRRS campaign: MIVIS mission on Sicilian volcanoes and ground measurements, Quad. Geofis., Pubblication n. 7, pp. 90.

Calvari, S., M. Coltelli, M. Neri, M. Pompilio and V. SCRIBANO (1994): The 1991-1993 Etna eruption: chronology and geological observations, Acta Vulcanol., 4, 1994, 1-14.

CRisp, J. and S. BALOGA (1990): A model for lava flows with two thermal componets, J. Geophys. Res., 95, 1255-1270.

DozIER, J. (1981): A method for satellite identification of surface temperature fields of subpixel resolution, $R e$ mote Sensing Environ., 11, 221-229.

FlynN, L.P., P.J. Mouginis-Mark and K.A. Horton (1994): Distribution of thermal areas on an active lava flow field: Landsat observations of Kilauea, Hawaii, July 1991, Bull. Vulcanol., 56, 284-296.

FlynN, L.P., A.J.L. HARris, D.A. ROTHERY and C. OPPEN- 
HEIMER (2000): High-Spatial resolution thermal remote sensing of active volcanic features using Landsat and hyperspectral data, in Remote Sensing of Active Volcanism, edited by P.J. Mouginis-MARK, J. FinK and J. CRISP, Geophys. Monogr. Ser., Am. Geophys. Union, 116, 161-177.

FlynN, L.P., A.J.L. HARRIS and R. Wright (2001): Improved identification of volcanic features using Landsat 7 ETM+, Remote Sensing Environ., 78, 180-193.

GauthiER, F. (1973): Field and laboratory studies of the rheology of Mount Etna lava, Philos. Trans. R. Soc. London Ser. A, 274, 83-98.

Glaze, L., P.W. Francis and D.A Rothery (1989): Measuring thermal budgets of active volcanoes by satellite remote sensing, Nature, 338, 144-146.

Global Volcanism Network (GVN) (1993a): Etna, Smithson. Inst. Bull. Global Volcan. Network, 02/93 (BGVN 18:02).

Global Volcanism Network (GVN) (1993b): Etna, Smithson. Inst. Bull. Global Volcan. Network, 03/93 (BGVN 18:03).

Global VolcanisM Network (GVN) (1996): Etna, Smithson. Inst. Bull. Global Volcan. Network, 07/96 (BGVN 21:07).

Global Volcanism NeTwork (GVN) (1999): Etna, Smithson. Inst. Bull. Global Volcan. Network, 06/99 (BGVN 24:06).

HARRIS, A.J.L. (1996): Low spatial resolution thermal monitoring of volcanoes from space, Ph.D Thesis, The Open University.

Harris, A.J.L., D.A. Rothery, R.W. Carlton, S. LangaAs and H. MANNSTEIN (1995): Non-zero saturation of AVHRR thermal channels over high temperature targets: evidence from volcano data and a possible explanation, Int. J. Remote Sensing, 16 (1), 189-196.

HARris, A.J.L., S. BlaKe and D.A. Rothery (1997): A chronology of the 1991 to 1993 Mount Etna eruption using advanced very high resolution radiometer data: implication for real-time thermal volcano monitoring, J. Geophys. Res., 102, 7985-8003.

Harris, A.J.L., L.P. FlynN, L. KeszThelyi, P.J. MouginisMark, S.K. Rowland and J.A. RESING (1998): Calculation of lava effusion rates from Landsat TM data, Bull. Vucanol., 60, 52-71.

Lombardo, V., M.F. Buongiorno, L. Merucci and D. Pieri (2003): Differences in Landsat TM derived lava flow thermal structures during summit and flank eruption at Mount Etna, J. Volcanol. Geotherm. Res. (in press).

MAtson, M. and J. DozIER (1981): Identification of subresolution high temperature sources using a thermal IR sensor, Photogramm. Eng. Remote Sensing, 47 (9), 1311-1318.
Mouginis-Mark, P.J., H. Garbeil and P. Flament (1994): Effects of viewing geometry on AVHRR observation of volcanic thermal anomalies, Remote Sensing Environ., 48, 51-60.

OPPENHEIMER, C. (1991): Lava flow cooling estimated from Landsat Thematic Mapper infrared data: the Lonquimay eruption (Chile, 1989), J. Geophys. Res., 96, 21865-21878

Pieri, D.C. and M.F. Buongiorno (2001): Systematic summit crater radiance increase as seen in Landsat TM data before the 1991-93 eruption on Mt. Etna, $J$. Volcanol. Geotherm. Res. (in review).

PIERI, D.C., L.S. GLAZE and M.J. ABRAMS (1990): Thermal radiance observation of an active lava flow during th June 1984 eruption of Mt. Etna, Geology, 18, 1018-1022.

Rothery, D.A., P.W. Francis and C.A. Wood (1988): Volcano monitoring using short wavelength infrared data from satellite, J. Geophys. Res., 93, 7993-8008.

Rothery, D.A., A. Borgia, R.W. CARlton and C. OppenHEIMER (1992): The 1992 Etna lava flow imaged by Landsat TM, Int. J. Remote Sensing, 13, 2759-2763.

Salvi, S., M.P. Bogliolo, M.C. Ferrari, M. Sgavetti, M. Boccolari, D. Campolieti, P. Frontero, S. Pugnaghi and S. Teggi (1992): Ground measurements at the Strait of Messina in support of the Multisensor Airborne Campaign - MAC Europe 1991, ING Publication n. 547.

Teggi, S., M.P. Bogliolo, M.F. Buongiorno, S. Pugnaghi and A. Sterni (1999): Evaluation of $\mathrm{SO}_{2}$ emission from Mt. Etna using diurnal and nocturnal MIVIS TIR remotesensing images and radiative transfer models, $J$. Geophys. Res., 104 (B9), 20,069-20,079.

WAN, Z. and J. DozIER (1989): Land-surface temperature measurement from space: physical principles and in verse modelling, IEEE Trans. Geosci. Remote Sensing, 27 (3), 268-277.

Wooster, M.J. and D.A. Rothery (1997a): Time series analysis of effusive volcanic activity using the ERS along track scanning radiometer: the 1995 eruption of Fernandina Volcano, Galapagos Island, Remote Sensing Environ., 69, 109-117.

Wooster, M.J. and D.A. Rothery (1997b): Thermal of Lascar volcano, Chile using infrared data from the along track scanning radiometer: a 1992-1995 time series, Bull. Vucanol., 58, 566-579.

Wright, R., P.F. FlynN and A.J.L. HARris (2001): Evolution of lava flow-fields at Mount Etna, 27-28 October 1999, observed by Landsat 7 ETM+, Bull. Vucanol., 63, $1-7$.

(received January 20, 2003; accepted December 5, 2003) 